\title{
Volume of emphysema
}

\author{
P TURNER, WF WHIMSTER \\ From the Department of Morbid Anatomy, King's College Hospital, London
}

\begin{abstract}
A method of determining the volume of emphysema in excised lungs is presented, with its validation. This method is based on macroscopic point counting using a perforated grid but only the holes (points) overlying emphysema need be counted to produce results within a percentage standard error of $5 \%$. Application of the method shows that an adequate assessment of emphysema cannot be made from one lung slice alone, and that the amount of emphysema found in one lung cannot be used to predict the amount of emphysema in the other lung.
\end{abstract}

Of the various methods devised to record the amount of emphysema present in human lungs, since the condition was more precisely defined, ${ }^{1}$ none has proved very satisfactory. These methods include assessment by point counting ${ }^{2}$ which produces a ratio or percentage value; a time-consuming internal surface area measurement using five random histological sections; ${ }^{3}$ and subjective methods, including that of comparing paper-mounted sections of whole lung slices with standard photographs. ${ }^{4}$ These methods produce a ratio or an arbitrary number as an end result, values which are not readily or easily transformed into a mental picture of the emphysema in that lung or pair of lungs.

We therefore set out to devise a method with which to measure, both quickly and accurately, the actual volume of emphysematous tissue present in a given lung. To this end we adapted the macroscopic point counting technique, ${ }^{2}$ so that only those points falling on the tissue of interest, in this case emphysematous tissue, need be counted, and so that an early calculation of the total number of points to be counted to give a predetermined percentage standard error could easily be made. In this paper we put forward this method together with its validation.

\section{Methods}

LUNG PREPARATION

Sixteen lungs (including three lung pairs) were obtained from necropsies. They exhibited little external damage, inflated well initially with an air pump, and were judged suitable for fixation.

Address for reprint requests: Dr WF Whimster, King's College Hospital Medical School, Denmark Hill, London SE5 8RX.
Fixation was achieved by intrabronchial inflation with $10 \%$ formaldehyde solution, using a head of pressure generated by keeping the level of the fixative $50-60 \mathrm{~cm}$ above the lung. ${ }^{5}$ As soon as the pleural surface appeared smooth and unfolded, inflation was discontinued, and the bronchus was clamped. The lung was then immersed in $10 \%$ formaldehyde for at least 24 hours. This simple method produces very good fixation and was perfectly adequate for our purposes. It does not produce the dramatic shrinkage of the lung found when using heated formalin vapour. Any resulting shrinkage may or may not be isotropic in nature. ${ }^{6} 7$ There is little risk of over-inflation, or distortion from the incompressibility of the fluid core ${ }^{7}$ which may sometimes occur when using constant heads of pressure. Finally, fixation is achieved rapidly in comparison with other techniques. ${ }^{5}$

\section{LUNG VOLUMES}

Lung volumes were then measured by water displacement. ${ }^{8}$ Measurements were accurate to within $10-20 \mathrm{~cm}^{3}$ and were made six times for each lung. From these readings the mean lung volumes, and their associated variances and standard deviations, were calculated. Ninety-five per cent confidence limits for the mean lung volumes were produced. These values formed the standards against which the accuracy of the point counting method was assessed.

\section{LUNG SLICES}

The inflated fixed lungs were placed, bronchus side up, in a perspex tray with $1.5 \mathrm{~cm}$ raised sides, and cut into sagittal slices with a sharp knife. Slices of relatively uniform $1.5 \mathrm{~cm}$ thickness were thereby obtained. 
Table 1 Total points required to give a standard error of $5 \%$

\begin{tabular}{|c|c|c|c|c|c|c|c|c|c|c|c|c|c|c|c|}
\hline \multicolumn{4}{|c|}{$\begin{array}{l}\mathbf{P} \text { (tissue proportion) } \\
\mathbf{N} \text { (total points required) }\end{array}$} & $\begin{array}{l}90 \% \\
45\end{array}$ & $\begin{array}{l}80 \% \\
100\end{array}$ & $\begin{array}{l}70 \% \\
172\end{array}$ & $\begin{array}{l}60 \% \\
267\end{array}$ & $\begin{array}{l}50 \% \\
400\end{array}$ & $\begin{array}{l}45 \% \\
489\end{array}$ & $\begin{array}{l}40 \% \\
600\end{array}$ & $\begin{array}{l}35 \% \\
743\end{array}$ & $\begin{array}{l}30 \% \\
934\end{array}$ & $\begin{array}{l}25 \% \\
1200\end{array}$ & $\begin{array}{l}20 \% \\
1600\end{array}$ & $\begin{array}{l}15 \% \\
2267\end{array}$ \\
\hline $\begin{array}{l}\mathbf{P} \\
\mathbf{N}\end{array}$ & $\begin{array}{l}10 \% \\
3600\end{array}$ & $\begin{array}{l}9 \% \\
4045\end{array}$ & $\begin{array}{l}8 \% \\
4600\end{array}$ & $\begin{array}{l}7 \% \\
5315\end{array}$ & $\begin{array}{l}6 \% \\
6267\end{array}$ & $\begin{array}{l}5 \% \\
7600\end{array}$ & $\begin{array}{l}4 \% \\
9600\end{array}$ & $\begin{array}{l}3 \% \\
12934\end{array}$ & $\begin{array}{l}2 \% \\
19600\end{array}$ & $\begin{array}{c}1 \% \\
39600\end{array}$ & $\begin{array}{r}0.5 \% \\
79600\end{array}$ & $\begin{array}{l}0.1 \% \\
399600\end{array}$ & & & \\
\hline
\end{tabular}

\section{POINT COUNTING}

The lung slices were placed successively, hilum side up, in a tray filled with water. A clear perspex sheet, in which holes $1 \mathrm{~mm}$ in diameter and $1 \mathrm{~cm}$ apart had been drilled in rows so that each formed the apex of equilateral triangles with adjacent rows, ${ }^{9}$ was lowered on to the surface of the water over the lung slice. The area on the perspex represented by each hole was therefore $0.866 \mathrm{~cm}^{2}$. As each lung slice was $1.5 \mathrm{~cm}$ thick each point on the lung represented a volume of $0.866 \times 1.5=1.299 \mathrm{~cm}^{3}$. A convention had to be adopted ${ }^{2}$ whereby holes overlying the edges of the slice were counted only at the top and left hand side of the grid and not at the bottom and right hand side.

The tissue lying beneath each hole was examined and categorised as: (1) parenchyma, (2) nonparenchyma (airways and blood vessels down to 1 $\mathrm{mm}$ in diameter), or (3) emphysema, the numbers of holes (points) being accumulated on a counter. After completion of the first total count for a lung (each slice counted once) an estimate of the tissue proportions present was made. For each of the component estimates, an uppermost value of the standard error could be obtained by use of the following equation:

$$
\text { Standard error }=\sqrt{\frac{P(100-P)}{N}} . . \text { eqn } 1
$$

where $\mathbf{P}=$ component percentage, and $\mathbf{N}=$ total number of points. It is an uppermost estimate because the points are not randomly distributed on the grid. ${ }^{9}$ Similarly, a percentage standard error may be deduced for each component:

Percentage standard error $(\mathrm{PSE})=$

$$
\frac{\text { standard error }}{\mathbf{P}} \times 100 \text {. eqn } 2
$$

We can now obtain the number of points $(\mathrm{N})$ that must be counted for each value of $P$ :

$$
\text { (from (1) and (2)) } N=\frac{P(100-P)}{\frac{(P S E . P)^{2}}{100}} . \quad . \text { eqn } 3
$$

We decided that we wished to keep the percentage error below $5 \%$. Using equation 3 , table 1 shows the total number of points that must be counted to give a percentage error of $5 \%$ for different proportions of emphysema or any other component and the figure

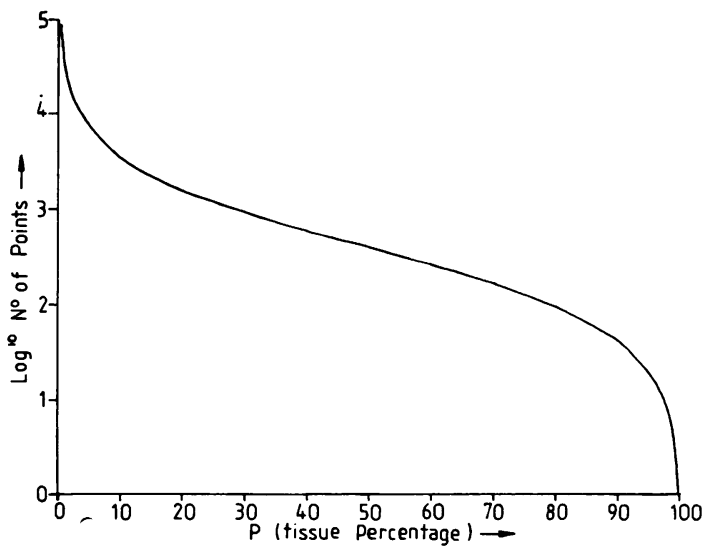

Figure Graph shows the log number of points that must be counted to obtain a percentage standard error (PSE) of $5 \%$ for any given percentage values $(P)$ for any tissue component, for example emphysematous tissue.

shows the same data expressed as a graph of $\log ^{10}$ $\mathbf{N}$ against $\mathbf{P}$. Having discovered the number of points required the number of times all the slices had to be counted was readily calculated.

These methods were used in the 16 lungs to determine the correlation between the lung volume obtained by water displacement and that obtained by point counting in non-emphysematous lungs, to obtain the actual volume of emphysema in the emphysematous lungs, and to compare the volume of emphysema in affected lung pairs. The method devised for the day-to-day measurement of the volume of emphysema in lungs as a result of these investigations is shown in appendix 2 .

\section{Results}

The results were recorded in table form, a separate table being used to record the values for each lung slice. The tables obtained were tested for homogeneity and freedom from bias (see appendix la). Ideally the tables should not exhibit too large a variance, nor, however, should the results appear too similar. The required degree of homogeneity was attained, in practice, by repositioning the grid over the lung slice after each count.

Of the 16 lungs examined 10 showed no emphysema on slicing and six were emphysematous. 
Table 2 Mean lung volumes $\left(\mathrm{cm}^{3}\right)$ by water displacement and by point counting

\begin{tabular}{|c|c|c|c|c|c|c|c|c|c|c|}
\hline $\begin{array}{l}\text { Normal } \\
\text { Displacement volume } \\
\text { Point count volume }\end{array}$ & $\begin{array}{l}1 \\
2518 \\
2603\end{array}$ & $\begin{array}{l}2 \\
1662 \\
1655\end{array}$ & $\begin{array}{l}3 \\
1847 \\
1867\end{array}$ & $\begin{array}{l}4(I) \\
1447 \\
1472\end{array}$ & $\begin{array}{l}4(I I) \\
1370 \\
1342\end{array}$ & $\begin{array}{l}5(1) \\
1772 \\
1773\end{array}$ & $\begin{array}{l}5(\text { II }) \\
1882 \\
1879\end{array}$ & $\begin{array}{l}6 \\
1462 \\
1474\end{array}$ & $\begin{array}{l}7 \\
2045 \\
2056\end{array}$ & $\begin{array}{l}8 \\
1977 \\
1966\end{array}$ \\
\hline $\begin{array}{l}\text { Emphysema } \\
\text { Displacement volume } \\
\text { Point count volume }\end{array}$ & $\begin{array}{l}1 \\
2075 \\
2089\end{array}$ & $\begin{array}{l}2 \\
2052 \\
2067\end{array}$ & $\begin{array}{l}3 \\
1712 \\
1725\end{array}$ & $\begin{array}{l}4(1) \\
2212 \\
2210\end{array}$ & $\begin{array}{l}4(\mathrm{II}) \\
2398 \\
2389\end{array}$ & $\begin{array}{l}5 \\
1852 \\
1847\end{array}$ & & & & \\
\hline
\end{tabular}

Total group: Correlation coefficient $r=+0.9978$; Regression line slope $=+1.0304$ (Regression equation $\left.y=-49 \cdot 42 \mathrm{~cm}^{3}+1 \cdot 0304\right)$ Emphysematous lungs: Correlation coefficient $=0.9993 ;$ Regression line slope $=0.9764$ (Regression equation: y $=+52.07+0.9764)$ Lungs marked 4(I) and 4(II) are pairs, 5(I) and 5(II) are a pair

\section{POINT COUNTING IN COMPARISON WITH WATER DISPLACEMENT}

Table 2 shows the mean lung volumes obtained for the 10 non-emphysematous lungs and the six emphysematous lungs by water displacement and by point counting. The mean volumes obtained by point counting consistently fell within the $95 \%$ mean volume range obtained by water displacement. The correlation coefficients indicate that there was a highly significant association between the two methods of measuring volume. Similarly, comparison of the regression coefficient with a hypothetical value of +1 showed that there were no significant differences between these two volumes either for the group as a whole or for the emphysematous lungs. Thus it was concluded that the point counting method provided a reliable estimate of lung volume both for non-emphysematous and for emphysematous lungs.

\section{COMPONENT VOLUMES}

Table 3 shows the component volumes and proportions present in the 10 normal and six emphysematous lungs. The variation present between the slices in each lung was tested (see appendix 1b) and it was found that in all 16 cases the component proportions varied significantly between the slices. This finding (which supports the previous work of Anderson and Dunnill ${ }^{2}$ ) shows that it is necessary to examine each slice, and that it is not possible to extrapolate from the values obtained for a single slice.

The percentage of non-parenchymatous tissue present may be regarded as a rough check of the degree of inflation achieved, a lung fully inflated having a non-parenchymatous proportion of about $10 \%$. Table 3 shows that all the lungs had a nonparenchymatous proportion of this order except for the emphysematous tumour-containing lung No 3.

EMPHYSEMA IN LUNG PAIRS

Table 3 also shows the results for one pair of emphysematous lungs. Using equation 4

$$
\begin{aligned}
& \mathrm{d}=\sqrt{\mathrm{k}(1-\mathrm{k})\left(\frac{1}{\mathrm{n}}+\frac{1}{\mathrm{n}_{2}}\right)} \\
& \text { where } \mathrm{k}_{1}=\frac{\text { emphysema points in lung } 1}{\text { total points in lung } 1\left(\mathrm{~N}_{1}\right)}
\end{aligned}
$$

\begin{tabular}{|c|c|c|c|c|c|c|c|c|c|}
\hline \multirow{2}{*}{$\begin{array}{l}\text { Lung } \\
\text { number }\end{array}$} & \multirow{2}{*}{$\begin{array}{l}\% \text { of volume } \\
\text { in lung pairs }\end{array}$} & \multirow{2}{*}{$\begin{array}{l}\text { Mean lung } \\
\text { volume }\left(\mathrm{cm}^{3}\right)\end{array}$} & \multirow{2}{*}{$\begin{array}{l}\text { Mean volume } \\
\text { standard } \\
\text { deviation } \\
\left(\mathrm{cm}^{3}\right)\end{array}$} & \multicolumn{3}{|c|}{ Non-parenchyma } & \multicolumn{3}{|l|}{ Emphysema } \\
\hline & & & & Percentage & $\begin{array}{l}\text { Standard } \\
\text { error }\end{array}$ & $\begin{array}{l}\text { Volume } \\
\left(\mathrm{cm}^{3}\right)\end{array}$ & Percentage & $\begin{array}{l}\text { Standard } \\
\text { error }\end{array}$ & $\begin{array}{l}\text { Volume } \\
\left(\mathrm{cm}^{3}\right)\end{array}$ \\
\hline 1 & - & 2518 & $26 \cdot 24$ & $9 \cdot 15$ & 0.31 & 230 & - & - & - \\
\hline 2 & - & 166 & 14.43 & 10.86 & 0.45 & 180 & - & - & - \\
\hline 3 & - & 1847 & $19 \cdot 45$ & $8 \cdot 59$ & $0 \cdot 37$ & 159 & - & - & - \\
\hline $4(I)$ & $51 \%$ right & 1447 & 25.66 & $14 \cdot 23$ & 0.52 & 206 & - & - & - \\
\hline 4(II) & $49 \%$ left & 1370 & $26 \cdot 68$ & $12 \cdot 70$ & 0.52 & 174 & - & - & - \\
\hline $5(I)$ & $48.5 \%$ left & 1772 & $24 \cdot 66$ & $12 \cdot 36$ & 0.45 & 219 & - & - & - \\
\hline $5($ II) & $51.5 \%$ right & 1882 & $30 \cdot 47$ & 11.94 & 0.43 & 225 & - & - & - \\
\hline 6 & - & 1462 & 22.99 & $11 \cdot 39$ & 0.47 & 166 & - & - & - \\
\hline 7 & - & 2045 & 44.06 & $8 \cdot 80$ & 0.36 & 180 & - & - & - \\
\hline 8 & - & 1977 & $27 \cdot 17$ & $8 \cdot 24$ & 0.35 & 163 & - & 一 & - \\
\hline 1 & - & 2075 & $21 \cdot 49$ & $10 \cdot 55$ & $0 \cdot 38$ & 219 & 23.56 & 0.53 & 489 \\
\hline 2 & - & 2052 & 52.62 & $9 \cdot 76$ & 0.26 & 200 & 3.04 & 0.15 & 62 \\
\hline $3 *$ & - & 1712 & $26 \cdot 24$ & $21 \cdot 21$ & 0.56 & 363 & $13 \cdot 70$ & 0.47 & 235 \\
\hline $4(I)$ & $48 \%$ left & 222 & 28.42 & $11 \cdot 92$ & 0.39 & 264 & $24 \cdot 58$ & 0.52 & 544 \\
\hline 4(II) & $52 \%$ right & 2398 & $30 \cdot 47$ & 11.84 & 0.38 & 284 & $19 \cdot 18$ & 0.47 & 460 \\
\hline 5 & - & 1852 & $21 \cdot 17$ & $8 \cdot 23$ & 0.36 & 152 & 8.02 & $0 \cdot 36$ & 149 \\
\hline
\end{tabular}

Table 3 Component volumes and proportions present in 10 normal and six emphysematous lungs

All percentage standard errors are below $5 \%$.

Note ${ }^{*}$ lung 3 , emphysema, also contained a secondary carcinoma, $3.07 \%\left(52.55 \mathrm{~cm}^{3}\right)$. 
$\mathrm{k}_{2}=\frac{\mathrm{P}_{2}}{\mathrm{~N}_{2}}$

$\mathrm{k}=\frac{\mathbf{P}_{1}+\mathbf{P}_{2}}{\mathrm{~N}_{1}+\mathbf{N}_{2}}$

to compare the proportions of emphysema within the two lungs gave $d=+6.42(p<0.001)$ which was a highly significant difference and indicates that assumptions about the amount of emphysema present in one lung cannot be made from that found in the other lung.

\section{Discussion}

Hitherto emphysema in excised lungs has generally been expressed as a percentage of the lung parenchyma, often after examination of a single slice or whole lung section ${ }^{10-12}$ and which this investigation has shown to be unreliable. In some studies the volumes of the lungs have been measured, or estimated from radiographs, in others the lung volumes have not been reported. ${ }^{13}$

When the point counting method has been used the lungs have usually been sliced after inflation and fixation and a Dunnill grid ${ }^{9}$ placed over each slice to count the points falling on normal parenchyma, emphysematous parenchyma and non-parenchyma. The points falling on emphysematous parenchyma have then been expressed as a percentage of all points counted. No attempt has been made to express this percentage of emphysematous parenchyma as an actual volume.

It would previously have been possible, knowing the fixed lung volume and the percentage of points falling on emphysematous lung, to have calculated the volume of emphysema in that lung but we were interested to know whether a point could, in practice, be regarded as representing a volume. That this is so is shown by the close correlation between the lung volume obtained by water displacement and that obtained by point counting the slices. If this is so, then only the points falling on the component under consideration, for example emphysematous parenchyma, need be counted to obtain the volume of that component.

This eliminates the need to count the large and distracting number of points falling on components which are not of interest. One can thus concentrate on observing the emphysema present, which is greatly helped by the discipline of having to observe each point. We wished, however, to ensure that the volume of emphysematous lung was reasonably accurate - that is, to within a percentage standard error of $5 \%$. This requires an initial idea of the proportion occupied by emphysema. Anderson and Dunnill $^{2}$ tackled this by using grids with different numbers of points, so that the required standard error was obtained by counting each slice only once with the appropriate total number of points. Our approach was to use the same grid several times after an initial emphysema count (see appendix 2). When the fraction of emphysema was known the total number of points still required to give a percentage standard error of $5 \%$ was obtained from table 1 or the figure and hence the number of times all the slices must be counted, re-siting the grid each time. Thus, in the example given in appendix 2 , the number of points that had to be counted was reduced from 5700 points to 456 points (114 points per time). Admittedly this did mean positioning the grid four times on each slice. These procedures having been validated, the emphysema in a lung can now be expressed as an actual volume.

The investigation also showed that the volume of emphysema found in one lung of a pair could not be used to predict the volume of emphysema in the other lung, although Haselton ${ }^{13}$ suggested that in a group of lung pairs the amount of emphysema found in the left lung group did not differ significantly from that in the right lung group.

This point illustrates one of the conflicts inherent in measurements of emphysema. On the one hand there is a need for epidemiological knowledge about the distribution of emphysema in different populations so that aetiological hypotheses can be tested. Thus, epidemiologically there may be little difference between the emphysema in groups of left lungs and the emphysema in groups of right lungs. On the other hand, there is a need to make a detailed assessment of the emphysema in individual patients to compare with detailed physiological and radiological measurements made in vivo. In these circumstances it is important to know that the emphysema in the left lung may differ significantly from that in the right lung.

We have to admit, however, that as with all previous forms of assessment, the bald statement of the volume of emphysema present gives little idea of its distribution or severity. Thus, $148 \mathrm{~cm}^{3}$ of emphysema, as in appendix 2, could represent a single bullous area of total lung destruction or 50 small foci, each occupying about $3 \mathrm{~cm}^{3}$. Thus at present the volume of emphysema must be accompanied by a qualitative statement in which some idea of the type, severity, and distribution is given, although attempts to quantify these aspects of emphysema in threedimensional terms are in progress.

Although the percentage of points falling on emphysema can be extrapolated to the volume of the lung ${ }^{2}$ we are sure that, in general, pathologists continue to think of point counting results in two dimensions. The same applies to Thurlbeck's 
"eyeball"4 and internal surface area methods. ${ }^{3}$ But lung tissue consists of elaborate three-dimensional relationships between air spaces, alveolar walls, and the "non-parenchyma" which services the alveolar walls. Emphysematous spaces result from damage, to the alveolar walls or the non-parenchymatous structures or both, whereby the normally efficient relationships between volumes of blood and volumes of air are disturbed. It cannot, therefore, be adequate to try to describe emphysema merely in terms of abnormal air spaces or in two dimensions. Threedimensional observations and descriptions in anatomy and pathology are, however, difficult to achieve. Nevertheless we believe that it is at least sensible to start by thinking of the abnormal air spaces volumetrically, particularly as it has been proved to be possible to reduce the labour of point counting as well as to bring it on to a firmer statistical basis. Finally we have not only found it more logical to use a transparent point counting grid with holes, through which the underlying tissue can be inspected, than with opaque points which obscure the underlying lung tissue, but also that the systematic inspection of the emphysematous tissue is conducive to three-dimensional appraisal.

We are indebted to the Joint Research Committee and the Special Trustees, King's College Hospital, for financial support.

\section{References}

${ }^{1}$ Ciba Guest Symposium Report. Terminology, definitions and classification of chronic pulmonary emphysema and related conditions. Thorax 1959;14:286-93.

2 Anderson JA, Dunnill MS. Observations on the estimation of the quantity of emphysema in the lungs by the pointsampling method. Thorax 1965;20:462-6.

${ }^{3}$ Thurlbeck WM. Internal surface area and other measurements in emphysema. Thorax 1967;22:483-96.

4 Thurlbeck WM, Dunnill MS, Hartung W, Heard BE, Heppleston AG, Ryder RC. A comparison of three methods of measuring emphysema. Hum Pathol 1970;1: 215-26.

${ }^{5}$ Sutinen S, Paakko P, Lahti R. Postmortem inflation, radiography and fixation of human lungs. Scand $J$ Respir Dis 1979;60:29-35.

6 Heard BE, Esterly JR, Wootliff JS. A modified apparatus for fixing lungs to study the pathology of emphysema.
Am Rev Respir Dis 1967;95:311-2.

7 Weibel ER. A note on lung fixation. Am Rev Respir Dis $1968 ; 97: 463-5$.

${ }^{8}$ Medical Research Council. Quantitative assessment of chronic non-specific lung disease at necropsy. Thorax $1975 ; 30: 241-51$.

' Dunnill MS. Quantitative methods in the study of pulmonary pathology. Thorax $1962 ; 17: 320-8$.

${ }^{10}$ Heard BE, Izukawa T. Pulmonary emphysema in fifty consecutive male necropsies in London. $J$ Pathol Bact $1964 ; 88: 423-31$.

${ }^{11}$ Roberts GH, Scott KWM. A necropsy study of pulmonary emphysema in Glasgow. Thorax 1972;27:28-32.

12 Hayes JA, Summerell JM. Emphysema in a non-industrialised tropical island. Thorax 1969;24:623-5.

${ }^{13}$ Hasleton PS. Incidence of emphysema at necropsy as assessed by point counting. Thorax 1972;27:552-6.

\section{Appendix 1}

\section{(a) Testing for homogeneity and freedom from bias}

The results obtained from each lung slice were tested for homogeneity and freedom from bias by showing that the individual counts did not appear too similar or have too large a variance. The chi-squared test was used. ${ }^{2}$ The results from a typical slice are shown in table 4. P lies between $95 \%$ and $5 \%$ so that the readings were neither too homogeneous nor too variable.

(b) Testing slice totals for variation between slices

The slice totals were tested to see whether the amount of emphysema differed from slice to slice or whether just one slice could be used as has previously been done. The results for one lung are shown in table 5. A highly

Table 4 Testing for homogeneity and freedom from bias in a single slice counted four times

\begin{tabular}{lccrl}
\hline & Parenchyma & Non-parenchyma & Totals $(T I)$ \\
\hline Count 1 & $371(368)$ & $29(32)$ & 400 & \\
Count 2 & $373(376)$ & $35(32)$ & 408 & \\
Count 3 & $378(375)$ & $29(32)$ & 407 & \\
Count 4 & $364(367)$ & $35(32)$ & 399 & \\
Totals (T2) & 1486 & 128 & 1614 & T (Grand \\
& & & & total) \\
\hline
\end{tabular}

The expected values (in brackets) are obtained by multiplying the totals T1 by the totals $T 2$ and by dividing the resulting value by the grand total T (eg $400 \times 128 \div 1614=31 \cdot 72)$

$x^{2}=\frac{\text { (observed-expected) }^{2}}{\text { expected }}=($ wo of rows $-1 \times$ no of columns -1$)$

In this case $\chi^{2}$ (with 3 degrees of freedom) $=1 \cdot 2368$. P lies between $95 \%$ and $5 \%$.

Table 5 Example of the variation between the slices of one lung

\begin{tabular}{rrrrr}
\hline & Parenchyma & Non-parenchyma & Emphysema \\
\hline (Lateral) slice 1 & $3089(2891)$ & $112(324)$ & $114(101)$ \\
slice 2 & $2878(2778)$ & $196(311)$ & $112(97)$ & 3315 \\
slice 3 & $2385(2080)$ & $419(289)$ & $120(89)$ & 2924 \\
slice 4 & $1340(1358)$ & $176(152)$ & 0 & $157)$ \\
(Hilar) slice 5 & $1409(1525)$ & $340(171)$ & 387 & 1749 \\
Totals T2 & 11101 & 1243 & Grand total (T) \\
\hline
\end{tabular}

$\chi^{2}($ with $5.1 \times 3-1=8$ degrees of freedom $)=555.08 . \quad \mathrm{p}<0.001(0.1 \%)$. 
significant variation between slices was found in this lung and in all the lungs examined. The results from a single slice are therefore not a reliable indication of the amount of emphysema in a lung.

\section{Appendix 2}

\section{Application of emphysema volume method}

1 Measure the volume of the fixed inflated lung by water displacement, taking the mean of three readings, ${ }^{8}$ eg Emphysema Lung 6, 1851.67 $c c=\frac{1851 \cdot 67}{1 \cdot 299} \equiv 1425$ points.

2 Slice the lung, on the slicing tray, into slices $1.5 \mathrm{~cm}$ thick.
3 Count the points falling on emphysematous tissue on the hilar surface of all slices,

$$
\text { eg } 115 \text { points, ie } \frac{115}{1425} \times 100=8.07 \%
$$

From table 1, between 4600 and 5315 total points are required for a percentage standard error of $5 \%$ for such a proportion of emphysema. This is equivalent to counting the slices between $3 \cdot 2\left(\right.$ (ie $\left.\frac{4600}{1425}\right)$ and $3 \cdot 7\left(\right.$ (ie $\left.\frac{5315}{1425}\right)$ times. 4 Count the set of slices three more times ( $\equiv 5700$ points), eg 456 points, ie mean emphysema count $=114$. Therefore emphysema volume $=114 \times 1.299=148 \mathrm{~cm}^{3}$ $=8 \%$ of $1851.67 \mathrm{~cm}^{3}$. 